\title{
A ATUALIdADE dA EDUCAÇÃO POLITÉCNICA COMO CONTRAPONTO À REFORMA DO ENSINO MÉDIO
}

\author{
THE ACTUALITY OF POLYTECHNIC EDUCATION AS A COUNTERPOINT IS THE REFORM OF \\ MIDDLE SCHOOL \\ LA ACTUALIDAD DE LA EDUCACIÓN POLITÉCNICA COMO CONTRAPONTO A LA REFORMA \\ DE LA ENSEÑANZA MEDIO
}

\author{
Marco Antônio de Oliveira Gomes \\ Universidade Estadual de Maringá \\ E-mail: marcooliveiragomes@yahoo.com.br \\ Gedeli Ferrazzo \\ Instituto Federal de Educação, Ciência e Tecnologia de Rondônia \\ E-mail: gedeli.ferrazzo@ifro.edu.br \\ Cláudia Barbosa Lobo \\ Faculdade Metropolitana de Rondônia \\ E-mail: claudiapvh@,hotmail.com
}

\begin{abstract}
RESUMO
Diante do avanço das reformas liberais e de suas bandeiras para educação, abordar o tema da educação politécnica é estratégico. É fundamental resgatar o fato de que uma formação integral contempla os aspectos intelectual, corporal e tecnológico. Cabe, portanto, identificar e estabelecer diferenças entre o que se convencionou chamar de educação integral de maneira mistificada e seu verdadeiro significado. Dessa forma, o presente trabalho se propõe a analisar a atualidade da educação politécnica como contraponto à reforma do ensino médio imposta por meio da lei $\mathrm{n}^{\circ} 13.415$, de 16 de fevereiro de 2017. Para tanto, partimos do princípio de que do ponto de vista da emancipação do trabalho frente ao capital, será necessária uma formação omnilateral, conceito de fundamental importância para a educação em Marx. Sendo assim, acreditamos que a leitura de Marx; Engels (2011), Pistrak, (2000), Alves (2006), Manacorda, (1996), entre outros, possa servir de suporte para uma análise sobre os significados das reformas em andamento, buscando apresentar alternativas que há muito são discutidas no âmbito de autores identificados com a educação politécnica.
\end{abstract}

PALAVRAS-CHAVE: Educação. Reforma. Ensino Médio. Politécnica.

\section{ABSTRACT}

Facing the progress of liberal reforms and their flags for education, addressing the issue of polytechnic education is strategic. It is fundamental to rescue the fact that an integral formation contemplates the intellectual, corporal and technological formation. It is therefore necessary to identify and establish differences between what is conventionally called integral education in a mystified form and its true meaning. Thus, the present work intends to analyze the actuality of polytechnic education as a counterpoint to the high school reform imposed by Law $n^{\circ}$. 13,415, of February 16, 2017. For this, we assume that from the point of view of Emancipation from work in front of capital will require on-the-ground training, a concept of fundamental importance for education in Marx. Therefore, we believe that the reading of Marx; Engels (2011), Pistrak, (2000), Alves (2006), Manacorda, (1996), among others, can serve as support for an analysis of the meanings of the reforms underway, finding to present alternatives that have long been discussed in scope Of authors identified with polytechnic education.

Keywords: Education. Reform. High school. Polytechnic.

\section{RESUMEN}

Ante el avance de las reformas liberales y de sus banderas para la educación, abordar el tema de la educación politécnica es estratégico. Es fundamental rescatar el hecho de que una formación integral contempla la 


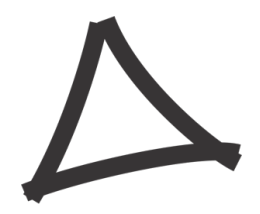

\section{Revista Triângulo}

formación intelectual, corporal y tecnológica. Cabe, por lo tanto, identificar y establecer diferencias entre lo que se ha convenido llamar de educación integral de forma mistificada y su verdadero significado. De esta forma, el presente trabajo se propone a analizar la actualidad de la educación politécnica como contrapunto a la reforma de la enseñanza media impuesta por medio de la ley $n^{\circ} 13.415$, de 16 de febrero de 2017. Para ello, partimos del principio que desde el punto de vista de la emancipación del trabajo frente al capital, será necesaria una formación omnilateral, concepto de fundamental importancia para la educación en Marx. Por eso, creemos que la lectura de Marx; (2006), Pistrak, (2000), Alves (2006), Manacorda, (1996), entre otros, pueda servir de soporte para un análisis sobre los significados de las reformas en curso, buscando presentar alternativas que desde hace mucho se discuten en el ámbito de autores identificados con la educación politécnica.

Palabras-clave: Educación. La reforma. Enseñanza Media. Politécnica.

\section{INTRODUÇÃO}

Não é novidade para aqueles que se propõem a compreender a dinâmica das relações capitalistas em sua totalidade que as crises que afetam o sistema não são acidentes. $\mathrm{O}$ capital não é capaz de resolver suas contradições ou mesmo de oferecer um padrão de desenvolvimento que elimine a miséria e o desemprego do planeta. Em outras palavras, o capital mantém-se destrutivo, desperdiçando recursos e mão de obra, tidos como descartáveis. Assim, é inegável que perdeu sua função civilizatória na medida em que aborta a vida e o sonho de milhares de trabalhadores.

No cenário da crise estrutural e de reestruturação do capital mundializado, que no Brasil intensificou-se fundamentalmente a partir da década de 1990, aceleraram-se transformações qualitativas nas formas de contratação e gestão da força de trabalho, interferindo intensamente no cotidiano do trabalhador. De fato, o avanço das proposições liberais no Brasil tem materializado significativos retrocessos se considerarmos as conquistas sociais da Constituição Federal de 1988. Não por acaso, é possível observar a redução do papel do Estado na garantia dos direitos sociais em nome da racionalidade do mercado.

Entendemos a necessidade de analisar o papel da educação nos processos de construção e manutenção da hegemonia burguesa, da mesma forma que se faz necessário desmontar o mito burguês que acena para o mercado como instância máxima de organização social e de equalização de oportunidades. Diante do exposto, o presente trabalho analisa a reforma do Ensino Médio em curso no país em um contexto marcado pelos ataques do capital à educação pública, caracterizando-se pelo acelerado processo de barateamento e 


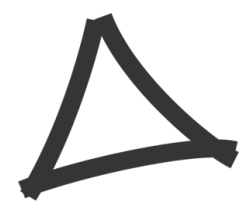

\section{Revista Triângulo}

esvaziamento das escolas mantidas pelo Estado, além de contribuir para a sua mercantilização.

De fato, na atual fase da crise estrutural do capitalismo, com a crescente omissão do Estado para as questões sociais, a escola torna-se um espaço estratégico para a sociabilidade burguesa, que propõe em linhas gerais a divisão entre trabalho intelectual e manual como instrumento de subordinação do trabalhador aos interesses do capital. No entanto, é evidente que esse processo não ocorre de forma linear, mas em uma relação dialética em razão da correlação de forças que estão em disputa na arena social.

Por fim, para além do propósito da análise das reformas em andamento, buscamos apresentar alternativas que há muito são discutidas por autores identificados com a educação politécnica. Portanto, não se trata de nenhuma novidade o que abordaremos a seguir, senão o desejo de reforçar a pertinência de uma proposta que se contraponha aos interesses do capital. Para tanto, partimos do princípio de que do ponto de vista da emancipação do trabalho frente ao capital, será necessária uma formação omnilateral, conceito de fundamental importância para a educação em Marx. Trata-se de uma proposta formativa em oposição àquela fornecida pelo Estado burguês, que se caracteriza fundamentalmente pela unilateralidade provocada pelo trabalho alienado e pela divisão do social do trabalho em uma sociedade dividida em classes.

\section{As origens da formação integral em uma perspectiva proletária}

O século XIX assistiu à consolidação do modo de produção capitalista, caracterizada pela relação entre os proprietários dos meios de produção (terra, fábricas, matéria-prima, conhecimentos etc.) e os trabalhadores "livres" que necessitavam vender sua força de trabalho no mercado para garantir a sobrevivência. Trata-se, na verdade, do ápice da produção histórica de trabalhadores disponíveis para o mercado, resultado de um processo violento de expropriação que nada tem a ver com suposições idílicas ou com a "natureza humana".

Assim, a figura do "trabalhador livre" constituiu-se no requisito fundamental para a existência do próprio capital. Por isso, na constituição histórica das relações capitalistas, o trabalho não atende ao propósito de produzir para satisfazer as necessidades do trabalhador, 


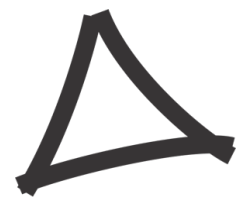

\section{Revista Triângulo}

mas do capitalista; e o primeiro transforma-se também em uma mercadoria em um mercado regulado pela existência do exército de reserva.

Segundo Marx; Engels, nessas circunstâncias, a força de trabalho do proletariado é "uma mercadoria como qualquer outro artigo de comércio" (1998, p.12) e "diferenças entre sexo e idade já não têm qualquer importância” (p.14) para os interesses da burguesia, que "abertamente proclama o lucro como sua finalidade exclusiva" (p.13). Como se vê, nada mais atual do que as análises de Marx e Engels.

É no século XIX, com a constituição da indústria moderna, que a mutilação do homem se consolida, "[...] que faz da ciência uma força produtiva independente de trabalho, recrutando-a para servir ao capital” (MARX, 1987, p.414). Isto posto, não é necessário avançar mais para compreendermos a essência predatória do capital que conduz à barbarização da vida social.

O trabalho na fábrica exaure os nervos ao extremo, suprime o jogo variado dos músculos e confisca toda a atividade livre do trabalhador, física e espiritual. Até as medidas destinadas a facilitar o trabalho se tornam meio de tortura, pois a máquina, em vez de libertar o trabalhador do trabalho, despoja o trabalho de todo interesse. Sendo, ao mesmo tempo, processo de trabalho e processo de criar mais valia, toda produção capitalista se caracteriza por o instrumental de trabalho empregar o trabalhador e não o trabalhador empregar o instrumental do trabalho [...] (MARX, 1987, p.483-484, grifos nossos).

Assim, ao mesmo tempo em que se produziam imensas riquezas, embruteciam-se os trabalhadores, afetando a vida de milhares de seres humanos. A "liberdade" conquistada resumia-se ao estar livre para ser explorado. Devido ao intenso processo de simplificação do trabalho, sucedeu a incorporação acelerada de mulheres e crianças à produção. $\mathrm{O}$ rebaixamento dos salários, gerada pela grande oferta de trabalhadores "livres", os ambientes caracterizados pela imundície determinaram não somente a sujeição do trabalhador masculino, mas igualmente a emergência de um quadro de miséria material e moral para os trabalhadores (ALVES, 2006).

O velho artesão, todo casa e oficina, para cujos filhos Lutero pedira duas horas de escola por dia ao lado do trabalho doméstico, não existe mais ou está desaparecendo: de qualquer forma, não é mais uma figura social determinante. Um século após Lutero, até Comenius, embora envolvido numa batalha religiosa de tipo medieval, já pensava como um homem moderno, quando indicava como lugares necessários para a formação do 


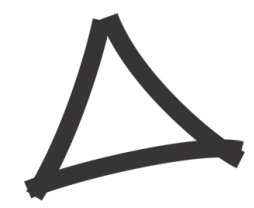

\section{Revista Triângulo}

homem também os armamentaria e os mercimoniorum loca, isto é, os canteiros navais e a bolsas da Holanda e da Inglaterra capitalistas. Em suma: a revolução industrial muda também as condições e as exigências de formação humana [...] Acontece, de fato, que o desenvolvimento industrial, tornado possível pela acumulação de grandes capitais, graças à exploração dos novos continentes descobertos, e de grandes conhecimentos científicos voltados não somente para o saber mas também para o fazer, traduz-se, do ponto de vista do artesão das corporações, num longo e inexorável processo de expropriação. Ao entrar na fábrica e ao deixar a oficina, o ex-artesão está formalmente livre, como o capitalista, também dos velhos laços corporativos; mas, simultaneamente, foi libertado de toda a sua propriedade e transformado em um moderno proletariado. Não possui mais nada; nem o lugar de trabalho, nem a matéria prima, nem os instrumentos de produção, nem a capacidade de desenvolver sozinho o processo produtivo integral, nem o produto do seu trabalho, nem a possibilidade de vendê-lo ao mercado. Ao entrar na fábrica, que tem na ciência moderna sua maior força produtiva, ele foi expropriado também da sua pequena ciência, inerente ao seu trabalho; esta pertence a outros e não lhe serve para mais nada e com ela perdeu, apesar de tê-lo defendido até o fim, aquele treinamento teóricoprático que, anteriormente, o levava ao domínio de todas as suas capacidades produtivas: o aprendizado (MANACORDA, 1996, p.271).

O processo, ao qual Manacorda se refere, sucede porque toda a produção em uma sociedade dividida em classes é apropriada pelas classes que controlam os meios de produção, restando aos grupos expropriados venderem sua força de trabalho em troca de um salário para a manutenção da sobrevivência. Ainda sobre a expropriação do trabalhador e sua condição de não liberdade, Karl Marx em Trabalho Assalariado e Capital, I, apresenta a seguinte constatação:

O operário não pertence nem a um proprietário nem à terra, mas $8,10,12$, 15 horas de sua vida diária pertencem a quem as compra. $\mathrm{O}$ operário abandona o capitalista ao qual se aluga tão logo o queira, o capitalista o despede quando lhe apraz, desde que dele não extraia mais nenhum lucro ou não obtenha o lucro almejado. Mas o operário, cujo único recurso é a venda de sua força de trabalho, não pode abandonar toda a classe dos compradores, isto é, a classe capitalista, sem renunciar à vida. Não pertence a tal ou qual patrão, mas à classe capitalista e cabe-lhe encontrar quem lhe queira, isto é, tem de achar um comprador nessa classe burguesa (MARX; ENGELS, 2011, p.28).

A correta percepção de Marx aponta para a falácia da "liberdade" do trabalhador sob o domínio do capitalismo. Trata-se, na verdade, de uma imposição própria do capital porque, ainda que os trabalhadores tenham "liberdade", não possuem as condições materiais para garantir a sua existência. É diante das novas circunstâncias impostas pelas transformações no 


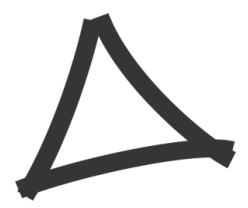

\section{Revista Triângulo}

âmbito da produção que devemos compreender a expansão da escola pública mantida pelo Estado. No processo de superação do modo de produção feudal pelo capitalista verifica-se uma nova dinâmica nas relações de trabalho e educação entre as classes sociais.

No cenário histórico caracterizado pelo crescente processo de industrialização no continente europeu, observa-se a ruptura das formas de aprendizagem voltadas para todos os passos do processo produtivo, tal qual ocorria na relação mestre e aprendiz, verificado nas oficinas e corporações de ofício que antecederam o advento da revolução industrial. A superação do artesanato pela manufatura, passando pela introdução das máquinas, supõe a formação de um novo tipo de trabalhador, adaptado à disciplina da fábrica. Além dessas questões, observa-se que o analfabetismo da absoluta maioria dos trabalhadores do campo e da cidade tornava inviável o rápido estabelecimento das inovações tecnológicas no "chão de fábrica". Nestas circunstâncias, o aparato escolar apresentava vantagens óbvias e que foram imediatamente aproveitadas pela burguesia.

Ainda no último quartel do século XVIII, com a Revolução Francesa (1789) levantaram-se bandeiras da escola como direito de todos. Era o momento em que a burguesia se manifestava como classe revolucionária contra os privilégios e o domínio da nobreza.

Não por acaso, verifica-se ao longo do século XIX a progressiva expansão da rede de escolas nas nações mais desenvolvidas da Europa. A expressão desse processo no campo educacional foi a crescente participação do Estado com vistas a conservar a ordem burguesa que se materializava. Manacorda (1996) ressalta que a Revolução Industrial, ao alterar a vida de milhares de trabalhadores, abriu espaço para o surgimento da moderna instituição escolar pública. Fábrica e escola são frutos de um mesmo processo. Porém, isso não implica em afirmar que a partir desse momento trabalhadores e burgueses frequentariam os mesmos bancos escolares. Pelo contrário, a escola reproduziu as divisões de classe. Queria dizer somente que os filhos da classe trabalhadora tiveram que começar a frequentar um local específico e formal para receberem uma formação condizente com o regime de trabalho nas fábricas e serem disciplinados.

A negação da escola para a classe trabalhadora, nos séculos XVI, XVII e XVIII, está diretamente relacionada com a necessidade histórica de braços para as manufaturas. Entretanto, a partir do início do século XIX, as manufaturas são progressivamente substituídas pela grande indústria, e a necessidade da classe burguesa passa a ser sobretudo a de se manter no 


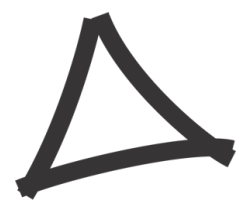

\section{Revista Triângulo}

poder politicamente. Nesse momento, a burguesia toma para si as reivindicações do proletariado e faz a defesa da escola para todos os cidadãos (LINS, 2003, p. 9).

A expansão da indústria pelo continente europeu exigiu um novo tipo de trabalhador. Já não era suficiente que o mesmo fosse resignado tal qual o servo medieval, ainda que isto continuasse sendo importante. Expropriado dos meios de produção, era um imperativo aceitar trabalhar para o burguês nas condições que este lhe impusesse. Se a coerção do Estado e o desemprego eram instrumentos de imposição da nova ordem econômica, a educação da infância proporcionava a conveniência de poder ser modelada segundo o credo do capital desde o início. Mesmo que pontilhados por tensões e conflitos, a expansão escolar se convertia em um apêndice dos interesses burgueses. As velhas instituições dos períodos pretéritos da Europa pré-capitalista, a família, o grêmio, a Igreja, entram em decadência, pois já não respondem às necessidades da sociedade industrial. Diante das contradições que se agudizavam com o capitalismo, a educação escolar constituiu-se em um dos instrumentos de disciplinamento da classe trabalhadora.

Acrescente-se que as circunstâncias históricas não permitiam ao Estado, legítimo representante dos interesses burgueses, restringir o acesso à educação escolar à classe trabalhadora.

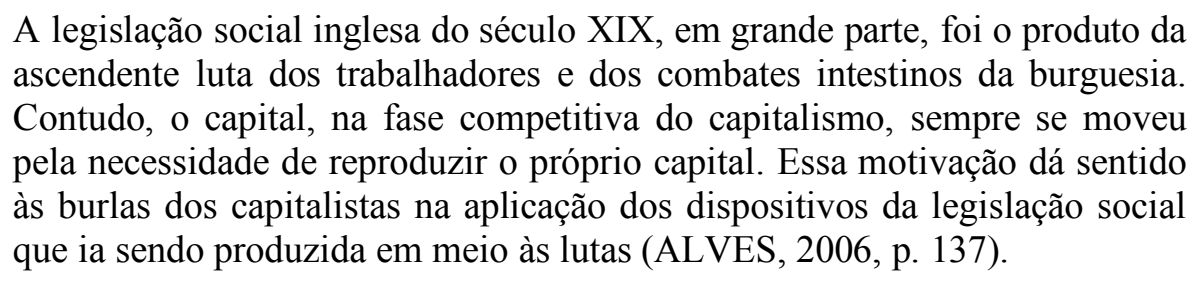

De fato, a legislação social inglesa, ainda que por vias contraditórias, contribuiu para o encarecimento da mão de obra infantil. Por outro lado, o desemprego gerado pela introdução de novas tecnologias a serviço do capital, constituía-se em uma ameaça social. Assim, a escola materializava-se como alternativa para preencher o tempo disponível dos jovens trabalhadores.

A ex-criança de fábrica, tendencialmente, se metamorfosearia em criança de escola. A escola transformou-se ao se constituir numa instituição social que prometia atender, além dos filhos dos capitalistas, também aos filhos recémdesempregados dos trabalhadores (ALVES, 2006, p.140). 


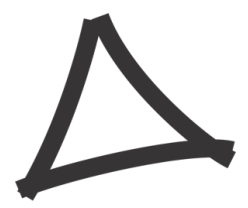

\section{Revista Triângulo}

Foi nesse momento que ganhou espaço a proposição burguesa de organização da escola pública, universal, laica, obrigatória e gratuita. No entanto, a artimanha utilizada pelo capital constituiu-se em ofertar a "igualdade" de oportunidades por meio da educação, a ponto de utilizar diferentes estratégias para não possibilitar aos filhos dos trabalhadores uma educação que permitisse o desvelamento das contradições da exploração do trabalho pelo capital. Dito de outra forma, a exclusão das classes populares ocorre de forma dissimulada, separando a formação burguesa, voltada para o ensino superior, e a formação proletária, com ênfase na prática e na aprendizagem para o trabalho.

A obliteração intelectual dos adolescentes, artificialmente produzida com a transformação deles em simples máquinas de fabricar mais-valia, é bem diversa daquela ignorância natural em que o espírito, embora sem cultura, não perde sua capacidade de desenvolvimento, sua fertilidade natural. Essa obliteração forçou finalmente o Parlamento inglês a fazer da instrução elementar condição compulsória para o emprego "produtivo" de menores de 14 anos em todas as indústrias sujeitas às leis fabris. O espírito da produção capitalista resplandecia vitorioso na redação confusa das chamadas cláusulas de educação das leis fabris, na falta de aparelhagem administrativa, que tornava frequentemente ilusória a obrigatoriedade do ensino, na oposição dos próprios fabricantes contra essa obrigatoriedade e nas suas manhas e trapaças para se furtarem a ela (MARX; ENGELS, 2011, p. 86).

Como contraponto ao modo de produção capitalista e ao domínio burguês, Marx e Engels propunham a transformação revolucionária da sociedade que fosse conduzida pelas mãos do proletariado. No entanto, era fundamental que os trabalhadores tomassem consciência da sua condição de classe para que o processo revolucionário fosse desencadeado.

\footnotetext{
Mas não cessa, nem mesmo por um instante, sua tarefa de formar nos trabalhadores uma consciência, tão clara quanto possível, do antagonismo hostil entre burguesia e proletariado, a fim de que os trabalhadores [...] possam voltar suas armas contra a burguesia - armas estas que são as condições políticas e sociais das quais a burguesia necessita para manter o seu domínio - e que assim tenha início imediatamente [...] a luta contra a própria burguesia (MARX; ENGELS, 2011, p.62).
}

Marx não abordou a questão educacional com o mesmo aprofundamento teórico e sistemático como o fez com o sistema capital, mas deixou elementos para sua compreensão. Nesse sentido, é consenso, entre aqueles que se debruçam sobre o tema "trabalho e educação", que o conceito "educação politécnica" foi delineado inicialmente por Marx no 


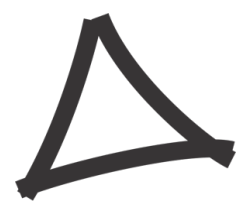

\section{Revista Triângulo}

interior de sua produção teórica em defesa do proletariado. Manacorda, em seu trabalho "Marx e a Pedagogia Moderna", adverte-nos que a "temática pedagógica é, de fato, tratada de maneira ocasional em seus aspectos específicos", dentro de um "contexto de uma crítica rigorosa das relações sociais" (1991, p.9).

Todavia, qual o significado da "educação politécnica" para o pensador alemão? Sem ambicionar esgotar a discussão, porque seguramente essa é uma tarefa bem complexa, excedendo os limites deste artigo, pode-se, inicialmente, ilustrar o pensamento marxiano por meio de uma das afirmações mais conhecidas de Karl Marx, retirada das Instruções aos Delegados do Conselho Central Provisório da Associação Internacional dos Trabalhadores, de 1868 (MARX; ENGELS, 2011, p.86): “afirmamos que a sociedade não pode permitir que pais e patrões empreguem, no trabalho, crianças e adolescentes, a menos que se combine este trabalho produtivo com a educação”. E, prosseguindo, Marx esclarece seu entendimento por educação:

Por educação entendemos três coisas: 1. Educação intelectual. 2. Educação corporal, tal como a que se consegue com os exercícios de ginástica e militares. 3. Educação tecnológica, que recolhe os princípios gerais e de caráter científico de todo o processo de produção e, ao mesmo tempo, inicia as crianças e os adolescentes no manejo de ferramentas elementares dos diversos ramos industriais (MARX; ENGELS, 2011, p.85).

Como se vê, trata-se de uma educação que considera a formação intelectual, corporal e tecnológica, constituída sob um processo de produção técnico-científico, na perspectiva de formação integral. Em outras palavras, a proposta marxiana aponta para a formação omnilateral.

Esta combinação de trabalho produtivo pago com a educação intelectual, os exercícios corporais e a formação politécnica elevará a classe operária acima dos níveis das classes burguesa e aristocrática. O emprego de crianças e adolescentes de nove a dezoito anos em trabalhos noturnos ou em indústrias, cujos efeitos sejam nocivos à saúde, deve ser severamente proibido por lei (MARX; ENGELS, 2011, p.86).

Como podemos notar, a preocupação de Marx e Engels não é uma volta às condições existentes antes da consolidação do capital. A proposta presente na defesa de uma educação politécnica não é um retorno das formas de instrução proporcionadas pela Igreja ou aquelas ofertadas pelas corporações de ofício, muito pelo contrário. Ambos estavam conscientes dos 


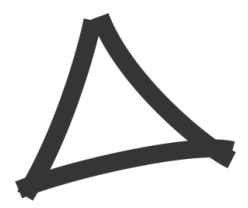

\section{Revista Triângulo}

imperativos que a sociedade industrial havia colocado em marcha, mas também da incapacidade burguesa de emancipar todos os homens.

Marx já reconhecia a necessidade de o trabalhador ser dotado de uma ampla visão de conjunto que tivesse acentuada capacidade de abstração, superando a superficialidade e executando atividades mais complexas ao afirmar que "[...] um homem que passa toda a sua vida fazendo algumas operações simples [...] não tem oportunidade de exercer sua inteligência [...] torna-se em geral o mais estúpido e ignorante possível” (MARX, 1969, p.78).

O princípio fundamental da organização é a ligação orgânica do ensino e da educação com o trabalho produtivo. A nova escola deve preparar os alunos para participarem do trabalho produtivo a partir de uma idade determinada e lhes assegurar a formação geral necessária para poder continuar seus estudos superiores. À base desse princípio, devem ser fixadas de maneira justa: a proporção do ensino geral, a do ensino politécnico e a do ensino profissional, combinando o ensino e o trabalho com repouso e o desenvolvimento físico normal das crianças e dos jovens. Assim, a ligação do ensino com a vida, com a produção e com a prática da edificação do novo regime social deve determinar o conteúdo, a organização e os métodos de ensino (LEMME, 2004, p.128).

Nesse sentido, em uma breve síntese, podemos afirmar que a educação politécnica parte do pressuposto de que o objetivo a ser alcançado, na perspectiva de uma sociedade justa, é a formação omnilateral, integral ou politécnica, que unifique o trabalho intelectual ao trabalho manual. Segundo Manacorda:

Que pode ser isso senão, exatamente, tudo aquilo que não é imediatamente útil, instrumental, operativo, isto é, a abertura àquele mundo das letras, das artes, da história, do pensamento que Marx, por seu lado, tão bem sabia apreciar? Talvez a chave para bem entender o pensamento de Marx esteja justamente aqui, no fato de que une, com austero rigor, a estrutura da escola à necessidade social de reproduzir a vida, de regular o intercâmbio orgânico com a natureza, em que a liberdade humana se explicita apenas como regulamentação racional desse intercâmbio [...]. (Manacorda, 2007, p. 108)

Poderíamos acrescentar que trata-se de uma proposição de ensino que articule práticas pedagógicas concretas que busquem romper com a profissionalização estreita por um lado, e com uma educação propedêutica, descolada do mundo do trabalho. Enfim, faz-se necessário uma escola que congregue conhecimento em suas diferentes áreas, cultura, trabalho, 


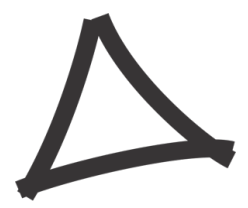

\section{Revista Triângulo}

tecnologia, além da formação física, tendo em vista a formação integral e a superação da sociedade de classes.

[...] a questão da relação entre o trabalho e a ciência perde todo o sentido ou, melhor dizendo, torna-se parte de um problema mais geral. O problema só podia ser colocado quando o ensino era separado da educação. Nossa escola deve liquidar esta separação. $O$ trabalho é um elemento integrante da relação da escola com a realidade atual, e neste nível há fusão completa entre ensino e educação. Não se trata de estabelecer uma relação mecânica entre o trabalho e a ciência, mas de torná-los duas partes orgânicas da vida escolar, isto é, da vida social das crianças (PISTRAK, 2000, p.49-50).

Ora, ainda não nos encontramos em um conjunto de relações sociais que proporcionem a materialização da proposta acima. No entanto, a escola pode ser considerada um espaço da luta de classes, e assim, pode potencializar uma possível transformação da sociedade. Não se trata de rendermo-nos a um idealismo estéril que enxerga na escola a panaceia para os problemas sociais, mas certamente cabe à educação um papel importante na construção da consciência por meio do acesso ao conhecimento.

Isto posto, antes de prosseguirmos, é necessário apontar que o ideário da educação politécnica esteve presente nas lutas em torno da defesa da educação pública na Constituição de 1988 e na LDB 9.394/96. Da mesma forma, a ideia de educação integral, ainda que dentro dos limites da ordem burguesa, constituíra-se em política pública em determinados momentos da história da educação brasileira. Registre-se as experiências do Centro Educacional Carneiro Ribeiro, concebida por Anísio Teixeira, durante a década de 1950, os CIEPs (Centro Integrado de Educação Pública), organizados por Darcy Ribeiro nos anos 1980. Já no último decênio do século XX, em função das demandas sociais, surgiram outras experiências inspiradas nos propósitos de Anísio Teixeira e Darcy Ribeiro, identificadas como propostas de Educação Integral. Constituíram-se em sua maioria de experiências organizadas pelos municípios e não se configurando um projeto político de maior amplitude, continuado e de governo.

Já no primeiro decênio deste século, no início do Governo de Luís Inácio Lula da Silva (2003-2006), verificou-se a retomada da proposição de uma "formação integrada", pelo Decreto n. 5.154/04, mas sem os fundamentos basilares da educação politécnica, processando-se por meio de programas focais e contingentes, fato já abordado por Frigotto; Ciavatta; Ramos. 


\section{Revista Triângulo}

Mais uma vez, na história da educação brasileira, com a eleição do presidente Lula da Silva em outubro de 2002, as expectativas de mudanças estruturais na sociedade e na educação, pautadas nos direitos inscritos na Constituição Federal de 1988, não se realizaram. Apesar da produção de conhecimentos sobre contradições, desafios e possibilidades da educação profissional, produzidas especialmente no âmbito da área Trabalho e Educação, que esperávamos ser apropriada pela política pública do Estado brasileiro, o que se revelou foi um percurso controvertido entre as lutas da sociedade, as propostas de governo e as ações e omissões no exercício do poder (FRIGOTO; CIAVATTA; RAMOS, 2005, p.1088).

Foge aos desígnios deste trabalho aprofundar as propostas sobre a educação integral no governo de Lula, mas enfatize-se que as mudanças ocorridas conservaram-se dentro dos limites do universo burguês. Além disso, o senso comum acaba por não diferenciar as variadas proposições a respeito da educação integral. Isto posto, cabe analisarmos a lei $\mathrm{n}^{\mathrm{o}}$ 13.415, de 16 de fevereiro de 2017, que ressalta a Reforma do Ensino Médio. Trata-se de uma medida que apresenta retrocessos e expressa o anacronismo das proposições burguesas em nosso país.

\section{A contrarreforma do Ensino Médio: a continuidade do dualismo educacional}

Como ponto de partida, é necessário o reconhecimento de que as pedagogias vinculadas à manutenção da ordem capitalista se inscrevem nas teorias pedagógicas identificadas com o neoprodutivismo, neoconstrutivismo e neotecnicista, conhecidas genericamente com as propostas do "aprender a aprender", que contribuem para o esvaziamento da educação escolar. Estas pedagogias hegemônicas são construídas, difundidas e defendidas pelas agências internacionais do capital com o propósito de adequar os trabalhadores e seus filhos a manutenção das relações de classe existentes.

Não se trata de uma novidade, mas é importante enfatizarmos que a educação em uma sociedade dividida em classes expressa tendencialmente os valores dos grupos dominantes, que buscam adaptar o indivíduo às normas estabelecidas pelo ideário burguês. O projeto privatista e mercadológico presente na lei $\mathrm{n}^{\mathrm{o}}$ 13.415, sem dúvida adequa-se perfeitamente aos interesses do capital.

Assim, a reforma deve ser compreendida como a expressão do processo de racionalização do Estado que busca atender aos interesses do mercado. Os alunos passam a 


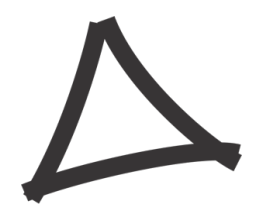

\section{Revista Triângulo}

ser considerados clientes cidadãos e as escolas, tal qual uma empresa, deverão atender as demandas da comunidade. No entanto, o que se oculta é que a escola não poderá atender as demandas dos seus alunos para a sua inserção no mundo do trabalho, e muito menos será garantida a suposta igualdade de oportunidades.

Em mensagem enviada à Presidência da República, EM no 00084/2016/MEC, o Ministro da Educação José Mendonça Bezerra Filho, expõe as razões da reforma:

4. Atualmente o Ensino Médio possui um currículo extenso, superficial e fragmentado, que não dialoga com a juventude, com o setor produtivo, tampouco com as demandas do século XXI. Uma pesquisa realizada pelo Centro Brasileiro de Análise e Planejamento - CEBRAP, com o apoio da Fundação Victor Civita - FVC, evidenciou que os jovens de baixa renda não veem sentido no que a escola ensina (BRASIL, 2016, grifos nossos).

Ora, como se vê, não há interesse na exposição do ministro Bezerra Filho em desvelar as razões estruturais da desigualdade. Dessa forma, a educação é apresentada como alternativa para os "jovens de baixa renda que não veem sentido no que a escola ensina".

Ainda conforme o documento, a reforma objetiva solucionar as baixas notas em avaliações institucionais e internacionais, além da alta evasão no ensino médio. Por isso, propõe um "novo modelo de Ensino Médio" que possibilitará "aprofundamento nas áreas do conhecimento", além de "cursos de qualificação, estágio e ensino técnico profissional de acordo com as disponibilidades de cada sistema de ensino", tudo alinhavado com as orientações presentes nas recomendações do "Banco Mundial e do Fundo das Nações Unidas para Infância - UNICEF". Ou seja, não se buscou o diagnóstico com os profissionais da educação ou nas entidades representativas da categoria.

Não por acaso, verifica-se no cenário atual o interesse renovado do empresariado na educação pública do Brasil travestida de "responsabilidade social". Obviamente, não se trata de algo novo em nosso país. Tal interesse explica-se pelo nicho de mercado que representa a educação, além de ser um espaço de difusão dos valores burgueses. Nesse sentido, diante do avanço das propostas liberais, a reforma do ensino médio é a expressão dos interesses burgueses. Não se trata apenas de reduzir conteúdos, mas de impedir o acesso a determinados conteúdos.

No entanto, como justificativa para a reforma, os problemas do ensino médio são apresentados como decorrência da composição curricular marcada pelo excessivo número de

\begin{tabular}{l|l|l|l|l|l|l|} 
(C) Rev. Triang. & Uberaba, MG & v.11 & n.1 & p. 102-124 & Jan./Abr. 2018 & ISSN 2175-1609
\end{tabular}




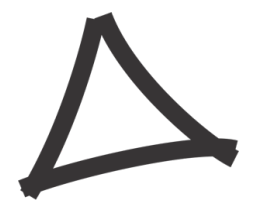

\section{Revista Triângulo}

disciplinas, "uma vez que a legislação vigente obriga o aluno a cursar treze disciplinas", sem levar em consideração as condições materiais de produção e manutenção da escola pública. Nesse sentido, ressalta-se que a lei $\mathrm{n}^{\circ} 13.415$, de 16 de fevereiro de 2017, ao estipular o currículo do Ensino Médio tendo por base percursos formativos por áreas do conhecimento, retrocede ao princípio da identidade estática, a uma compreensão esfacelada do desenvolvimento humano, cuja premissa balizadora se fundamenta em uma concepção cartesiana de educação, amparada no ideal de homem- máquina, imperando o caráter estático e unilateral da educação.

Trata-se de uma proposta, como é possível observar no documento, que tem " como principal determinação a flexibilização do Ensino Médio, por meio da oferta de diferentes itinerários formativos", sem ter em conta que os problemas do Ensino Médio não podem ser dissociados da realidade material do país, que muito tem contribuído para aprofundar a precariedade em todas as dimensões da vida, principalmente para os filhos da classe trabalhadora.

Ao apontar para "a flexibilização do Ensino Médio, por meio da oferta de diferentes itinerários formativos", a lei relega a escola a um mero espaço de reprodução, de aplicação da prática pela prática. De modo que fortalece a naturalização, a reprodução das desigualdades sociais ao negar as formas clássicas de educação escolar para os filhos da classe trabalhadora.

Nesse sentido, não há dúvidas de que o atual modelo do Ensino Médio reproduz as desigualdades históricas e não condiz com as necessidades dos trabalhadores, o que se propõe, na verdade, é justamente o reforço das desigualdades. Senão, vejamos o texto da lei $\mathrm{n}^{\mathrm{o}} 13.415 / 2017$, Art. $35, \S 3^{\circ}$ : “O ensino de língua portuguesa e matemática será obrigatório nos três anos do Ensino Médio" E as outras áreas do conhecimento? Não seria um artifício do Estado que, por meio da lei, se vê desobrigado a contratar professores para outras áreas?

Art. $36, \S 5$. Os sistemas de ensino, mediante disponibilidade de vagas na rede, possibilitarão ao aluno concluinte do Ensino Médio cursar, no ano letivo subsequente ao da conclusão, outro itinerário formativo de que trata $o$ caput (BRASIL, 2017).

Em outras palavras, as vagas serão asseguradas na rede de ensino de que modo? Ora, a reforma aprovada dispõe que $60 \%$ do currículo será composta por disciplinas obrigatórias e os $40 \%$ restantes serão optativas. Assim, no decorrer do curso, os alunos deverão optar entre cinco áreas: linguagem e suas tecnologias, matemática e suas tecnologias, ciências da 


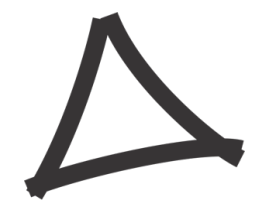

\section{Revista Triângulo}

natureza e suas tecnologias, ciências humanas e sociais aplicadas ou formação técnica profissional. Acrescente-se que a carga horária passará das atuais 800 horas anuais para 1400 horas.

Considerando-se que há municípios de pequeno porte com apenas uma ou duas escolas, é lícito questionar se as opções elencadas possibilitarão a "oferta de diferentes itinerários formativos". Verifica-se, dessa forma, o avanço da lógica privatista que ocorre por meio da omissão do Estado em manter a educação pública, contribuindo para o crescimento das desigualdades educacionais, com maior prejuízo para os filhos da classe trabalhadora.

É importante ressaltar igualmente para o déficit de professores presentes em diferentes Estados da União. Um exemplo emblemático desse fenômeno encontramos nos cursos de Matemática:

O número de cursos de Matemática e a proporcionalmente escassa procura por eles não condiz com a extensa presença e a importância desse componente curricular na educação básica. Esse dado sugere que devem faltar professores de Matemática para atender as necessidades das redes escolares. Segundo os mencionados estudos do Inep realizados em 2006, haveria apenas em torno de $27 \%$ de professores de Matemática com formação específica na área. (GATTI; BARRETO, 2009, p. 74)

Então, não bastasse a negação implícita do acesso ao Ensino Médio a todos, a lei cria brechas para a contratação de docentes com "notório saber reconhecido pelos respectivos sistemas de ensino para ministrar conteúdos de áreas afins à sua formação" com objetivo de atender o que estabelece a nova organização curricular. Ou seja, o MEC não resolve o problema da formação de professores e do déficit presente em diferentes áreas do conhecimento, mas trata de legalizar o processo de precarização das condições de trabalho e formação docente.

Para além da omissão anunciada no texto da lei que regulamenta a Reforma do Ensino Médio, proclama um aporte de recursos destinados ao melhoramento da infraestrutura escolar nos diferentes Estados da União que aderirem ao novo modelo de implantação do Ensino Médio Integral, contudo determina um limite de escolas e estudantes por estado. Verifica-se, por exemplo, que serão atendidas no máximo 572 escolas, em todo o universo de escolas mantidas pelo poder público. Quanto ao número de alunos atendidos, o máximo previsto é de 257.400 para um total aproximado de 6.770.271 de estudantes matriculados (censo de 2015). 


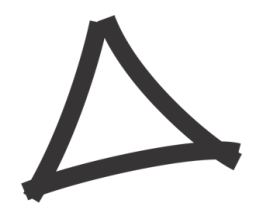

\section{Revista Triângulo}

Além disso, para receber recursos a escola precisa ter no mínimo 350 alunos matriculados no Ensino Médio.

Diante do exposto, a perspectiva anunciada é de fechamento de escolas, algo que já ocorre em diferentes Estados da Federação, como é o caso de São Paulo e Paraná. Ora, o Brasil possui uma dívida secular para com os trabalhadores, que historicamente foram impedidos do acesso ao conhecimento, senão aqueles que fossem importantes no aspecto da produção. Será que a limitação de alunos e escolas atendidas é o caminho para superação dos problemas da educação?

Além desses aspectos, chama-nos atenção o fato de que "os conteúdos cursados durante o Ensino Médio poderão ser convalidados para aproveitamento de créditos no Ensino Superior", o que implica no rebaixamento e desvalorização da produção acadêmica na educação superior. O que se explicita na lei não representa apenas o descompromisso do Estado ou a irresponsabilidade daqueles que governam, mas uma forma lucrativa de esvaziamento da escola destinada aos filhos da classe trabalhadora. Não é só um estímulo à desigualdade, mas também à desqualificação.

A reforma apresenta-se como a materialização de um projeto privatista e mercadológico que expressa e reforça as divisões já existentes na história da educação no Brasil, ou seja, uma escola para aqueles que compõe os segmentos da classe dominante, e um outro modelo para aqueles que terão um ensino técnico de qualidade duvidosa.

$\mathrm{Na} \mathrm{EM} \mathrm{n}^{\mathrm{o}}$ 00084/2016/MEC, o Ministro Bezerra Filho justifica a necessidade da reforma, amparada no critério de desempenho apresentado pelos estudantes do Ensino Médio, sem questionar as razões materiais para tanto.

13. Isso é reflexo de um modelo prejudicial que não favorece a aprendizagem e induz os estudantes a não desenvolverem suas habilidades e competências, pois são forçados a cursar, no mínimo, treze disciplinas obrigatórias que não são alinhadas ao mundo do trabalho, situação esta que, aliada a diversas outras medidas, esta proposta visa corrigir, sendo notória, portanto, a relevância da alteração legislativa (BRASIL, 2016).

Como se vê, trata-se de uma proposta alinhada com os interesses dos homens de negócios que desejam trabalhadores flexíveis e prontos para submeter-se aos caprichos do capital. Tal discurso se fundamenta em um pragmatismo vulgar, que tão bem caracteriza o ideário neoliberal, legitimando o imediatismo e a superficialidade do cotidiano alienado. Uma 


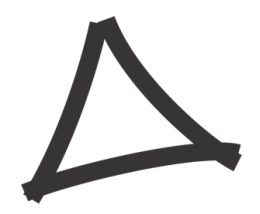

\section{Revista Triângulo}

das consequências mais perversas desse discurso, se estabelece pela via da sua utilidade prática cotidiana do conhecimento, que resulta na negação das formas clássicas de educação escolar para a classe dominada, e que por consequência fortalecem e naturalizam a reprodução das desigualdades sociais.

$\mathrm{O}$ argumento de possibilitar "um ensino médio atrativo para o jovem, além da liberdade de escolher seus itinerários” esconde a naturalização das desigualdades presentes na sociedade brasileira. Dentro da perspectiva liberal, cada indivíduo escolhe seu caminho, o que implicará em uma formação mínima para muitos. Dessa forma, se legitima ideologicamente a perpetuação da sociedade capitalista, se retira da escola a função de assegurar a socialização do conhecimento clássico e necessário para a transformação da sociedade. Trata-se, enfim, de reduzir o espaço formativo do jovem trabalhador, perpetuando o lugar de formação dos filhos das classes proletárias.

Ressalte-se que a "liberdade de escolha" pelos estudantes, dos itinerários formativos não passa de um engodo, já que a oferta das cinco (05) opções depende exclusivamente das condições das escolas em torná-las realidade. Isso se aplica também ao anúncio da instituição da Política de Fomento à Implementação de Escolas de Ensino Médio em Tempo Integral, em virtude da maioria das escolas públicas apresentarem um déficit histórico de infraestrutura e de recursos humanos para operacionalizar a expansão da jornada escolar. Isso também implica no acesso ao Ensino Médio, pois 23,6\% dos estudantes necessitam trabalhar e estudar no período noturno.

Todavia, a expansão do tempo integral para o Ensino Médio, não representa a premissa de uma formação integral do aluno, como anuncia o artigo $35, \S 7$ ․:

Os currículos do Ensino Médio deverão considerar a formação integral do aluno, de maneira a adotar um trabalho voltado para a construção de seu projeto de vida e para sua formação nos aspectos físicos, cognitivos e socioemocionais (BRASIL, 2017, grifos nossos).

Contrário a uma formação integral dos educandos, a reformulação do Ensino Médio, ao instituir os itinerários formativos e a obrigatoriedade de ensino nos três anos do Ensino Médio apenas das disciplinas de Matemática, Língua Portuguesa e Língua Estrangeira, incide diretamente na fragmentação e até mesmo na insolvência do pleno desenvolvimento humano. 


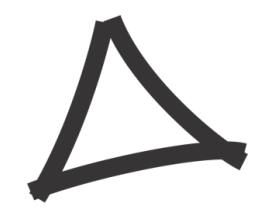

\section{Revista Triângulo}

Divergente do texto do $\S 3^{\circ}$, do Artigo 35, o qual define a obrigatoriedade do ensino da Língua Portuguesa e da Matemática nos três anos do Ensino Médio, o texto do $\S 2^{\circ}$, do mesmo artigo, apenas anuncia a inclusão obrigatória de "estudos e práticas de Educação Física, Arte, Sociologia e Filosofia". Destaca-se que essas áreas, anteriormente disciplinas obrigatórias em todos os anos do Ensino Médio, passam a ter um caráter transversal e facultativo, já que se definem enquanto "estudos ou práticas", podendo ser diluídas em outras disciplinas (BRASIL, 2017).

Além de prever a flexibilização do ensino, a proposta enaltece a oferta do ensino médio à distância ou mediado por tecnologia, o que consagra a verdadeira intenção mercadológica e reducionista da reforma.

Art. 36. $\S 11$. Para efeito de cumprimento das exigências curriculares do ensino médio, os sistemas de ensino poderão reconhecer competências e firmar convênios com instituições de educação a distância com notório reconhecimento, mediante as seguintes formas de comprovação: VI - cursos realizados por meio de educação a distância ou educação presencial mediada por tecnologias (BRASIL, 2017, grifos nossos).

A enaltecer as formas de oferta do Ensino Médio, cabe destacar que em diversos estados brasileiros, o ensino médio público já é ofertado de acordo com os preceitos da educação a distância ou do então chamado modelo de "mediação tecnológica". Tais modelos representam uma manobra mercadológica do estado na tentativa de cumprir com a universalização do ensino médio, de forma precária e reducionista, que abalizam percursos aligeirados de certificação vazia, os quais não proporcionam nem mesmo condições de competição no mundo do trabalho. Assim, não se pode deixar de perguntar: que contribuições a reforma poderá oferecer aos filhos da classe trabalhadora?

É, dessa forma, um modelo asfixiante, que procura suprimir as possibilidades de emancipação dos estudantes diante das espontâneas inferências com o mundo do trabalho. $\mathrm{Ou}$ seja, a reforma em curso procura adequar os jovens ao conformismo de adequação às relações sociais vigentes. Com o argumento da necessidade de flexibilizar a formação e torná-la mais atrativa aos alunos, o governo acaba por empobrecer o currículo com a exclusão de disciplinas de formação geral, importantes para uma compreensão crítica da sociedade e seus determinantes materiais. 


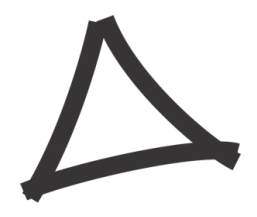

\section{Revista Triângulo}

Não por acaso observa-se que a Reforma está em consonância com as bandeiras levantadas pelo movimento da Escola Sem Partido, movimento surgido em 2004. Seus proponentes partem do pressuposto de que nas escolas públicas ocorre uma "doutrinação ideológica de esquerda", contra a qual o Estado deve opor resistência por meio do controle legal. Trata-se de mais uma estratégia dos apóstolos do capital de controle da educação, que culminou na tramitação do projeto de lei 193/2016, cujo propósito é incluir entre as diretrizes e bases da educação nacional o programa Escola sem Partido. Programa esse que representa de fato a imposição de um Estado de ideologia única, por meio da educação. Na verdade, ao retirar a obrigatoriedade das disciplinas de Filosofia e Sociologia, opera-se um movimento semelhante ao verificado ao longo da Ditadura Civil-Militar no Brasil (1964-1985). De fato, há um propósito articulado entre as propostas presentes na lei e os objetivos da burguesia que deseja imprimir seu "DNA" no projeto educativo. Nada mais atual que as palavras de Marx; Engels: "A cultura, cuja perda o burguês lamenta, é, para a imensa maioria, um adestramento que transforma os homens em máquinas" (1998, p.25).

As mudanças sugeridas pelo Estado brasileiro, por meio do Ministério da Educação, não devem ser compreendidas como alheias às transformações que se processam na produção capitalista. Trata-se de um ajuste às exigências demandadas por esta última.

No contexto da reestruturação produtiva passa a ser um diferencial na concorrência intercapitalista obter o comprometimento e a participação dos trabalhadores de chão de fábrica na forma de sugestões e projetos sobre o sistema produtivo no dia-a-dia no local de trabalho (SANTANA et al., 2012, p.199).

Por isso, se por um lado a exclusão da Filosofia e Sociologia representa o enxugamento do currículo e igualmente da contratação de professores, o que converge com o ideário liberal, por outro, deseja-se a preparação e adequação dos jovens para o mundo do trabalho sem os "vícios" de uma potencial formação crítica. Inibir intelectualmente os filhos da classe trabalhadora, limitar suas potencialidades de leitura consequente das crises inerentes ao capitalismo e da realidade social em todas as dimensões econômica, ideológica, social e política é, sem dúvida, parte de um processo maior marcado pelo aguçamento da crise estrutural do capital. Em outras palavras, a predominância dos interesses burgueses e a sua hegemonia sobre a totalidade das relações sociais colidem com a ideia de emancipação do homem, considerado tão somente a partir do que pode produzir enquanto força de trabalho. 


\section{Revista Triângulo}

Trata-se, na verdade, de uma tendência contínua do capital em expropriar o trabalhador dos meios de sua subsistência, que incide também sobre as conquistas sociais, incluindo o direito à educação, cuja mercantilização resulta no reforço do dualismo educacional. Ressalte-se que essa tendência não é decorrente de uma simples economia de recursos objetivando o bem estar social, mas resulta de uma totalidade de relações sociais exacerbadas pelas expropriações que sustentam a dinâmica capitalista.

É importante enfatizar que a forma pela qual foi imposta a lei, sem o diálogo com as entidades representativas do campo educacional, coaduna-se com outras ações em curso no Brasil que objetivam a redução do orçamento público para as questões sociais ao mesmo tempo em que se busca disciplinar o futuro trabalhador, o que mantém viva a essência da dívida secular para com os filhos da classe trabalhadora: a de serem impedidos de terem acesso ao conhecimento, a não ser aqueles que fossem imprescindíveis ao trabalho produtivo no campo ou no espaço fabril.

\section{CONSIDERAÇÕES FINAIS}

Toda política educacional deve ser compreendida dentro do momento histórico da sociedade que a engendrou, refletindo e contribuindo para um projeto societário. Cabe-nos questionar qual é o projeto de sociedade que orienta as decisões unilaterais do Estado, sem amplo debate, especialmente sem a participação das entidades representativas dos educadores e estudantes.

A reforma do Ensino Médio instituída pela lei $\mathrm{n}^{\circ}$ 13.415, de 16 de fevereiro de 2017, como procuramos demonstrar, não busca superar a histórica exclusão dos filhos da classe trabalhadora ao acesso ao conhecimento, mas a reforça. Verifica-se mais uma vez a não superação da divisão entre educação propedêutica versus educação profissional. Logo, a propaganda oficial do governo de "liberdade de escolha" dos jovens não passa de engodo, a fim de asfixiar e suprimir o desenvolvimento iminente dos jovens.

Ironicamente, na apresentação da ainda Medida Provisória 746/2016, o ministro da Educação, Mendonça Filho, afirmou que o "novo Ensino Médio tem como pressuposto 


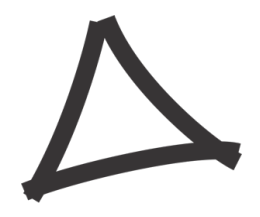

\section{Revista Triângulo}

principal a autonomia do jovem. É muito comum o jovem colocar que aquela escola não é a escola que dialoga com ele". Porém, se a escola não dialoga com o estudante, a reforma se fez de forma autoritária, imposta por meio de medida provisória. Trata-se, como demonstramos anteriormente, de adestrar a mão de obra aos propósitos da burguesia

Dessa forma, a partir das condições disponíveis, devemos procurar alternativas para a superação dos limites impostos pelo capital com vistas a sua superação. Essa luta não prescinde da educação. Se a educação politécnica não é possível sob a égide do capital, faz-se necessário acumular forças entre os trabalhadores para a construção de alternativas no campo educacional de modo a fortalecer a luta contra o capital. Nesse sentido, o marxismo, por trazer implícita uma dada filosofia, cuja raiz é o homem e sua emancipação, parece-nos a matriz epistemológica adequada para fundamentarmos a formação das novas gerações.

Ao propor a educação intelectual, física e tecnológica, Marx apontava claramente para a formação integral dos trabalhadores, ou seja, uma formação omnilateral. Acrescente-se que defendia a educação como formação humana integral para todas as crianças. Essa compreensão de formação foi incorporada à tradição marxiana sob a designação de educação politécnica, em função das próprias referências do autor ao termo, bem como de grande parte dos estudiosos de sua obra.

Em síntese, é possível afirmar que politecnia supõe uma nova forma de integração das diferentes áreas do conhecimento, que supera os bloqueios artificiais que transformam as disciplinas em compartimentos estanques, expressão da fragmentação da ciência. Assim, Marx tinha muito claro que a materialização da educação politécnica só seria viável em uma sociedade emancipada, com a superação do capitalismo.

Caberia aos trabalhadores organizados arrancarem do Estado a educação que lhes convém. O objetivo é claro: que os trabalhadores readquiram o domínio sobre o conteúdo do próprio trabalho e, assim, tenham maiores possibilidades de luta pela superação da alienação e, por conseguinte, do próprio capitalismo.

Apesar de todas as adversidades que enfrentamos, é imprescindível nos posicionar. É necessário aproveitarmos todas as brechas existentes e utilizarmos os espaços disponíveis. Não resta dúvida de que se não nos organizarmos para superar a sociedade existente, estaremos condenados a nos contentar com as migalhas ofertadas pelo capital. 


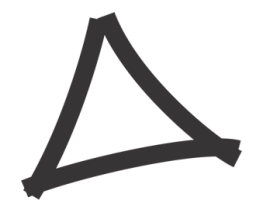

\section{Revista Triângulo}

Calar diante da crescente barbárie significa aceitar a continuidade da dominação burguesa. A riqueza da experiência revolucionária russa deixou-nos um importante legado que não deve ser esquecido jamais. Assim, nada mais pertinente que o conselho de Marx e Engels (1998): proletários de todo mundo, uni-vos.

\section{REFERÊNCIAS}

ALVES, G. L. A produção da escola pública contemporânea. Campinas: Autores Associados, 2006.

BRASIL. Medida Provisória n. ${ }^{\circ}$ 746, de 22 de setembro de 2016. Institui a Política de Fomento à Implementação de Escolas de Ensino Médio em Tempo Integral, altera a Lei $\mathrm{n}^{\mathrm{o}}$ 9.394, de 20 de dezembro de 1996, que estabelece as diretrizes e bases da educação nacional, e a Lei $\mathrm{n}^{\mathrm{o}} 11.494$ de 20 de junho 2007, que regulamenta o Fundo de Manutenção e Desenvolvimento da Educação Básica e de Valorização dos Profissionais da Educação, e dá outras providências. Diário Oficial [da] República Federativa do Brasil, Brasília, DF, 2016. Disponível em: <https://www25.senado.leg.br/web/atividade/materias/-/materia/126992>. Acesso em: 14 mar 2017.

BRASIL. Lei n. ${ }^{\circ}$ 13.415, de 16 de fevereiro de 2017. Altera as Leis nos 9.394, de 20 de dezembro de 1996, que estabelece as diretrizes e bases da educação nacional, e 11.494, de 20 de junho 2007, que regulamenta o Fundo de Manutenção e Desenvolvimento da Educação Básica e de Valorização dos Profissionais da Educação, a Consolidação das Leis do Trabalho - CLT, aprovada pelo Decreto-Lei no 5.452, de 1o de maio de 1943, e o Decreto-Lei no 236, de 28 de fevereiro de 1967; revoga a Lei no 11.161, de 5 de agosto de 2005; e institui a Política de Fomento à Implementação de Escolas de Ensino Médio em Tempo Integral. Diário Oficial [da] República Federativa do Brasil, Brasília, DF, 2017. Disponível em: $<$ http://www.planalto.gov.br/ccivil_03/_ato2015-2018/2017/lei/L13415.htm $>$. Acesso em: 14 abr 2017.

BRASIL. Portaria n. ${ }^{\circ}$ 1.144, de 10 de outubro de 2016. Institui o Programa de Fomento à Implementação de Escolas em Tempo Integral, criada pela Medida Provisória no 746, de 22 de setembro de 2016. Brasília, MEC, 2016. Disponível em: $<$ http://portal.mec.gov.br/index.php?option $=$ com docman\&view $=$ download\&alias $=49121$ port-1145-11 out-pdf\&category slug=outubro-2016-pdf\&Itemid=30192>. Acesso em: $15 \mathrm{abr}$ 2017.

FRIGOTTO, Gaudêncio. A produtividade da escola improdutiva. 9.ed. São Paulo: Cortez, 2010. 


\section{$\Delta$}

\section{Revista Triângulo}

FRIGOTTO, Gaudêncio; CIAVATTA, Maria; RAMOS, Marise. A política de educação profissional no Governo Lula: um percurso histórico controvertido. Educação e Sociedade. v.26, n.92, Campinas, 2005.

GATTI, Bernadete Angelina; BARRETO, Elba Siqueira de Sá. Professores do Brasil: impasses e desafios. Brasília: UNESCO, 2009.

LEMME, Paschoal. 1904-1997 Memórias de um educador. Brasília: Inep, 2004.

LINS, Ana M. M. Educação Moderna: contradições entre o projeto civilizatório burguês e as lições do capital. Campinas: Autores Associados, 2003.

MANACORDA, M. A. História da Educação: da antiguidade aos nossos dias. 10.ed. São Paulo: Cortez, 1996.

MANACORDA, M. Marx e a pedagogia moderna. Campinas: Alínea, 2007.

MARX, Karl; ENGELS, Friedrich. Textos sobre educação e ensino. Campinas: Navegando, 2011

MARX, Karl. O Capital. Trad.: de Ronaldo Alves Schmidt. Rio de Janeiro: Zahar, 1969.

MARX, Karl. O capital. v.2. Rio de Janeiro: Civilização Brasileira, 1998.

MARX, Karl. O Capital: crítica da Economia Política. 11.ed. São Paulo: Bertrand Brasil DIFEL, 1987.

NOSELLA, Paolo. Trabalho e Educação. In: GOMEZ, Minayo Carlos et al. Trabalho e conhecimento: dilemas na educação do trabalhador. São Paulo: Cortez, 2012.

PISTRAK, M. M. Fundamentos da escola do trabalho. São Paulo: Expressão Popular, 2000 .

SANTANA, F. P. et al. Globalização, relações interfirmas e trabalho no século XXI. Revista História e Perspectivas, Uberlândia, v.46, n.181-208, jan./jun. 2012. Disponível em: $<$ http://www.seer.ufu.br/index.php/historiaperspectivas/article/viewFile/19452/10447>. Acesso em: 09/04/2017.

SAVIANI, Dermeval. Educação socialista, pedagogia histórico-crítica e os desafios da sociedade de classes. In: José Claudinei Lombardi; Dermeval Saviani (Orgs.). Marxismo e educação: debates contemporâneos. Campinas: Autores Associados: Histedbr, 2005. 